\title{
CONSIDERAÇÕES SOBRE A IMITAÇÃO ENTRE JOVENS E CRIANÇAS CEGAS
}

\author{
Maria Rita Campello Rodrigues \\ Instituto Benjamim Constant e Universidade Federal Fluminense
}

Marcia Oliveira Moraes

Universidade Federal Fluminense

\begin{abstract}
Resumo
O artigo investiga a imitação entre jovens e crianças cegas. A pesquisa foi realizada como um mosaico no tempo já que as considerações de campo foram extraídas de dois domínios: da experiência profissional com a estimulação precoce de bebês cegos e de dispositivo de intervenção com jovens cegos e com baixa visão, com idades entre 13 e 18 anos. Afirmando o caráter situado do conhecimento, a pesquisa indica que a imitação entre jovens cegos pode ser uma das vias de criação de um mundo comum entre cegos e videntes. A imitação entre jovens cegos é um processo que envolve múltiplas sensorialidades, exige experimentação do corpo e redunda numa transformação recíproca, tanto do cego quanto do vidente. O trabalho conclui com a indicação do caráter singular da imitação e, ao mesmo tempo, com a afirmação da sua pertinência ao processo de inclusão e desenvolvimento tanto da criança quanto do jovem cegos.
\end{abstract}

Palavras-chave: educação especial; imitação; cegueira; corpo.

\section{ON IMITATION AMONG YOUNG AND BLIND CHILDREN}

\begin{abstract}
This article investigates the imitation among young and blind children. The survey was conducted as a mosaic in the time since the field considerations were taken from two areas: a professional experience with early stimulation of blind babies and a workshop with blind and low vision young between 13-18 years. By stating the situated trace of knowledge, the research indicates that imitation among blind young people can be one of the ways of creating a common world among young blind and sighted people. Imitation among blind young is a multi-sensory process that requires a body experience, including both blind and people who see. The paper concludes with an indication of the unique character of imitation and at the same time, with the affirmation of its relevance to the development and inclusion process of both the child and the young blind.
\end{abstract}

Keywords: special education; imitation; blindness; body.

\section{CONSIDERACIONES SOBRE LA IMITACIÓN DE JÓVENES Y NIÑOS CIEGOS}

\begin{abstract}
Resumen
El artículo investiga la imitación entre jóvenes y niños ciegos. La investigación se realizó como un mosaico en el tiempo, las consideraciones de campo fueron tomadas de dos áreas: la experiencia profesional de la estimulación temprana de los bebés ciegos y el dispositivo de intervención con jóvenes ciegos y con baja visión, con edades entre 13 y 18 años. Afirmando el conocimiento como práctica situada, la investigación indica que la imitación entre los jóvenes ciegos puede ser una forma de creación de un mundo común entre ciegos y videntes. La imitación entre los jóvenes ciegos es un proceso que implica múltiples sensorialidades, requiere experimentación del cuerpo y equivale a una transformación recíproca del ciego y del que ve. El documento concluye con una indicación del carácter único de la imitación, con la afirmación de su relevancia para el proceso de inclusión y desarrollo para el niño y el joven ciego.
\end{abstract}

Palabras clave: educación especial; imitación; ceguera; cuerpo. 


\section{INTRODUÇÃO}

Este artigo se propõe a refletir sobre a questão da imitação e a representação como tópico extraído da pesquisa de campo realizada com jovens e crianças cegas e com baixa visão, alunos do ensino fundamental do Instituto Benjamin Constant (IBC); a partir do estudo que constituiu a tese de doutorado da primeira autora do estudo (Rodrigues, 2013). Trata-se de um texto produzido em parceria entre pesquisadora e orientadora, uma composição, ora no plural, principalmente no que se refere ao método, ora no singular, quando a prática se torna exigida. O Instituto Benjamin Constant é um centro de referência nacional na área da deficiência visual, desenvolvendo atividades voltadas para a educação da criança cega e com baixa visão, tanto no campo da estimulação precoce, quanto no dos segmentos infantil e fundamental da educação. Além disso, o IBC oferece atividades de reabilitação para adultos cegos, bem como atendimento médico oftalmológico.

Salientamos desde já que adotamos uma concepção educacional da baixa visão, que abrange um largo espectro que pode variar entre um grau mínimo, no limite da cegueira e um grau de visão mantida (residual), próximo do limite daquele que enxerga. Esse grau pode se concentrar na visão central, na periférica ou em nenhuma delas especificamente. Na maior parte dos casos, as pessoas que têm baixa visão guardam uma percepção do mundo que se aproxima mais daquele que vê do que daquele que é cego. A abordagem educacional da baixa visão, assim como a sua conceituação clínica (médica), pode ser conhecida mais detalhadamente em Brasil (2001).

Destacamos como extratos do campo duas práticas distintas: uma, referente às situações do presente, e outra, à experiência profissional de muitos anos de atuação da primeira autora nessa área. Os extratos retirados da prática atual, isto é, do presente, foram colhidos das oficinas de expressão e experimentação corporal com os jovens que se interessaram e aceitaram participar da pesquisa, conforme as normas vigentes para a ética em pesquisa com seres humanos, constituindo seu campo disparador, onde ela se deu mais especificamente. $E$, os extratos referentes ao passado, da experiência de 30 anos de trabalho profissional no atendimento às crianças, no Setor de Estimulação Precoce, compondo o que definiremos nas linhas a seguir como mosaico.

O dispositivo da oficina foi criado exclusivamente com a finalidade da pesquisa, não fazendo parte das atividades regulares do IBC. Seus participantes eram jovens alunos do $4^{\circ}$ ao $9^{\circ}$ ano do Ensino Fundamental com idades entre 13 e 18 anos e, formavam um grupo que variava entre cinco e dez, porém, nem todos, tiveram uma participação contínua. Alguns eram cegos congênitos, outros foram perdendo a visão ao longo da vida e ainda outros apresentavam baixa visão. As oficinas aconteciam uma vez por semana com uma hora e meia de duração, no palco do teatro do Instituto e perfizeram um período total de dois 
anos e oito meses de funcionamento. Elas eram previamente planejadas com atividades que mobilizassem o corpo e que pudessem ser interessantes aos alunos. Seu planejamento guardava certa flexibilidade a fim de podermos seguir as sugestões e pistas que nos eram fornecidas pelos próprios participantes.

\section{DESENVOLVIMENTO}

Nosso mosaico pretende expressar o sentido de conformações múltiplas, de conexões, vínculos e realidades que se produziam no campo. A escrita do presente artigo segue a diretriz de um mosaico tecido com pedaços-cacosfragmentos de tempos distintos, ora aqueles oriundos das práticas atuais, na oficina de expressão corporal, ora aqueles oriundos das experiências anteriores, no campo da estimulação precoce com crianças cegas e com baixa visão (Rodrigues, 2002; Rodrigues \& Macário, 2006). As peças do nosso mosaico foram gradativamente sendo selecionadas, experimentadas e arranjadas como em uma rede sem uma estrutura prévia, anterior ou predeterminada.

Assim, afirmamos que este texto é escrito como um mosaico, pois a política de escrita que adotamos traz algumas cenas das práticas, que são narradas e aparecem com o subtítulo: Inter-Ações. As cenas que marcam se apresentam com uma formatação distinta, grafadas em itálico, destoando do resto do texto. Decidimos não as datar aqui por considerarmos este procedimento desnecessário. Neste campo, deve-se apresentar uma introdução ao método.

Então, método e política de escrita seguirão um manejo e uma conformação inspirada pela arte do mosaico. O texto, sua escrita, as narrativas que dele fazem parte, as conexões e memórias encarnadas ou lembradas das práticas pretendem seguir a pista sugerida por Despret (2012), no sentido de fazer cumprir uma promessa de disseminação. Escrever é tornar matéria um pensamento, uma ideia, uma prática; é concretizá-los, colocá-los no mundo, disseminá-los, deixá-los ir, em última instância com o vento no tempo e no espaço.

Afinamo-nos com o pensamento de Mol (2008) e Kastrup (2013) de que a realidade é "performada", múltipla e produzida nas práticas cotidianas com base na maneira como as coisas se interferem e se conectam. Mol (2008) investe na ideia de que a interferência pode produzir um desvio, um deslocamento de partes que se encontram, podendo fazer proliferar novas versões da realidade. Em nossa pesquisa, pretendemos interferir para questionar antigas e provocar novas concepções que articulam corpo e cegueira e baixa visão nos afastando das concepções que tratam a cegueira como falta e a baixa visão como déficit.

Para acompanharmos esse processo, criamos um dispositivo de pesquisa e de escrita que vai trazer à tona certa prática. Prática essa feita de ações que envolvem o cotidiano escolar, pois se realiza dentro da escola, com jovens e 
crianças cegas e com baixa visão e, o nosso cotidiano no lidar com eles, a que chamamos neste texto de Inter-Ação.

Interessa-nos investigar, nesse cenário, as articulações que envolvem a relação corpo e cegueira e baixa visão, tanto no que se refere ao trabalho dedicado às crianças da Estimulação Precoce quanto aos jovens da oficina com a pesquisa atual.

Existem algumas linhas de descontinuidade e outras de continuidade entre esses dois movimentos. As linhas de descontinuidade estão nos modos distintos de lidar e tratar, sendo um com crianças entre zero e cinco anos de idade, conforme a prática de muitos anos, focada no desenvolvimento infantil, e o outro, com os jovens no dispositivo das oficinas, atual, em que não é necessário ensinar ou estimular a rolar, sentar e andar. Assim, é proposta outra prática, que traz uma promessa de liberdade e possibilidade de inovação que experimentamos agora na pesquisa.

Há, contudo, uma linha de continuidade que se impõe não só por si mesma, pelo tema de interesse, que consiste na relação entre corpo e cegueira e baixa visão, mas também por uma continuidade que se instala no campo, tendo como ponto de partida o presente que convoca alguma coisa do passado.

Percebemos, em muitos momentos, esses pontos de contato como um contágio, como se alguns poros se abrissem permitindo certa mistura entre esses movimentos. Há nessa comunicação, no entanto, algo que é imponderável, pois talvez só a prática encarnada explique por si mesma o ponto exato no qual um fato do presente faz conexão com algo do passado e o traz à tona.

Desse modo, esclarecemos que as Inter-Ações são recortes extraídos dos diários de campo do dispositivo da oficina com os jovens que em alguns momentos chamam a experiência com as crianças no passado, e a reatualizando nesse presente. A escolha dos recortes não é aleatória, requer especial atenção, pois há algo no campo que sinaliza os pontos importantes, os que permitem compreender a relação entre corpo e cegueira e baixa visão na prática, de modo situado, que é atravessado por um viés efetivamente lúdico e criativo. Destacamos neste artigo a questão da imitação e da representação que persistentemente se presentificava quando corpo, cegueira e baixa visão interagiam.

Quanto à política dos nomes dos participantes da pesquisa mencionados nesse artigo são todos fictícios, contudo, sua escolha seguiu uma diretriz. Foram selecionados de acordo com personagens do universo infanto-juvenil, pois havia uma forte tendência lúdica nas atividades propostas ou por algum traço especial que se fizesse presente. Suas escolhas se deram pela intensidade que cada nome escolhido traz consigo e não por uma identidade fixa de cada personagem. À medida que eles aparecem no texto, segue uma observação situando se o jovem é cego ou se tem baixa visão e a sua idade. 
Assim, compomos nosso mosaico como uma alegoria em processo, adotando-o como método: o método do mosaico, seguindo insistentemente, imanentes com a prática.

Inter-Ação

Todos de pé, em roda, com o elástico grosso (encapado de malha) fechado em círculo, passando por trás de nossos corpos, trabalhamos em conjunto as dissociações de cinturas pélvica e escapular, com base nas movimentações do tronco com o estímulo da música. Ao final, Luluzinha [jovem cega, com 17 anos] comentou que mexer a cintura com o elástico foi bom, pois se sentia meio dura.

Luluzinha se referiu à sensação de ter o corpo duro, um tanto rígido, e que as atividades corporais com música ajudavam a torná-lo um pouco mais ágil. Heimers (1970) afirma que, muitas vezes, a falta de estímulos adequados na infância pode gerar dificuldades que se prolongam pela vida toda. Ele completa seu pensamento sublinhando que:

Os movimentos dos cegos são geralmente hesitantes e tímidos, limitando-se ao estritamente necessário. Os músculos e membros não relaxam, mantêm uma certa rigidez, a respiração é como que ofuscada. A parte superior do corpo não acompanha os movimentos ao andar, a cabeça é inclinada para [a] frente ou dobrada na nuca, as pernas levantam-se alto demais e os pés pisam com cuidado exagerado (Heimers, 1970, p. 46).

Embora os trabalhos de Heimers datem dos anos 70 do século $\mathrm{XX}$, muitas de suas afirmações ainda são pertinentes e largamente retomadas por outros autores como Pozzana (2013), Sampaio (2013), Carpentieri (2001) e Silva e Grubits (2004).

Com a prática do trabalho psicomotor (Rodrigues, 2013) que é realizado com as crianças da Estimulação Precoce no IBC, podemos afirmar que este deve ser um trabalho continuado, jamais abandonado ou interrompido, mesmo quando a criança já está mais crescida. As atividades psicomotoras são fundamentais para o desenvolvimento da pessoa cega e com baixa visão. Elas vão influir na conquista da autoconfiança e autonomia das percepções espaçotemporais e da orientação e mobilidade com independência (Latour, 2012; Pozzana, 2013; Manso, 2010).

Inter-Ação

Voltamos ao assunto da música. Todos acharam ser ela necessária, pois instiga os movimentos. Nessa hora, chamou-me a atenção o comentário discreto de Sherlock [jovem cego, com 18 anos], quase murmurando: "Meu corpo é muito preso", e, logo em seguida, Luluzinha concordando, disse: "Eu também me sinto muito dura". Observamos no relaxamento inicial a dificuldade de alguns em soltar os movimentos da cintura escapular; os ombros eram mantidos elevados, ficando mais próximos das orelhas, como se estivessem meio presos à cabeça. 
Ao som da música Bolero de Ravel e sentados em roda orientamos que dançassem somente com a cabeça naquele ritmo, assim como se ela representasse todo o corpo; depois, que incluíssem pouco a pouco os ombros nesse movimento e, por fim, o tronco superior até a cintura. Observamos movimentos duros e retos em alguns dos jovens, e continuamos: "Vamos procurar fazer movimentos redondos, como uma onda do mar". Sherlock estranhou: "Ih! O que é isso, como é que se faz uma onda do mar? Não sei como é uma onda do mar". Aproximei-me e por trás fiz os movimentos ondulatórios junto com ele, ao que comentou: "Ih! A tia tem ginga"! Fomos a cada dupla mostrando como eram os movimentos redondos, fazendo juntos.

O pouco manejo com o corpo presente em grande parte das pessoas cegas é um fato que sempre nos chamou a atenção, em especial a uma de nós, na prática de docência no IBC. A falta de molejo se mostra por uma postura um tanto rígida, caminhar tenso e movimentos pouco flexíveis, sem as dissociações de cinturas próprias da marcha e, adicionalmente, muitos alunos cegos e com baixa visão apresentam dificuldade de se expressar corporalmente (Pozzana, 2013; Rodrigues, 2013; Gurgel \& Moraes, 2014).

Os comentários dos jovens sobre a sensação que têm de seus corpos vêm corroborar o que já havíamos encontrado em outras oportunidades de exercício profissional. A tensão da musculatura que assumem parece atuar como fator de proteção à dor quando obstáculos são frequentes e inesperados no cotidiano das pessoas. Elas ficam mais facilmente expostas a pancadas e quedas, que poderiam ser evitadas com a visão. Essa suposição se confirma, pois a postura protetora é mais frequente quando se movimentam em locais que Ihes são pouco familiares.

A oficina de expressão corporal vem, então, abrir espaço para esses jovens com a ambição de quebrar essa carapaça e produzir "outro corpo", promovendo a conexão com outros elementos, com uma diversidade de materiais (bola, argila, bambolês), com os colegas, com a música, com o ambiente, estimulando movimentos mais livres e soltos, na intenção de produzir um corpo mais confiante de si, bem diferente daquele que mais parecia uma armadura. A oficina propõe atividades com certo grau de ludicidade, promovendo também a expressividade corporal.

Neste ponto surge a instigante questão da imitação. Representar determinados movimentos, como os das ondas do mar ou o do voo de pássaros, da mesma maneira que os videntes, seria significativo para esses jovens cegos ou quase cegos? Reproduzir determinados movimentos como os videntes facilitaria sua aceitação e inclusão em seu meio social? Seria recomendável ensinar tais movimentos, fazendo junto com eles, corpo a corpo, para que percebessem suas nuanças e detalhes, já que não imitam pela visão? Ou isso seria tolher a espontaneidade e minar qualquer possibilidade de criatividade?

Consideramos crucial a questão da imitação em nossa pesquisa. Há de se ter delicadeza em abordá-la, pois nada está dado de partida, há um movimento 
de fazer e refazer que exige especial atenção e cuidado de nossa parte. Faz-se necessária uma boa dose de sensibilidade para perceber e entrar em sintonia com os distintos momentos e situações de vida por que passa a pessoa cega e com baixa visão, razão de nosso estudo. Não há como generalizar. É preciso acolher as particularidades que vão se apresentando.

Como apontam muito bem Moser (2000) e Manso (2010), não concebemos a ideia de normalização. Ao se colocar o cego fazendo como o vidente, temos o efeito inverso: mais se torna evidente sua diferença, seja em um detalhe, um trejeito, na falta de molejo. Com outras palavras, a questão da imitação entre crianças e jovens cegas nos coloca justamente diante do desafio de intervir no cenário da deficiência visual sem, no entanto, impor o referencial do vidente como modelo a ser seguido. Moser (2000) indica que as práticas de reabilitação, e também as de educação das pessoas com deficiência são, muitas vezes, orientadas por um princípio de normalização, isto é, por uma ambição de restituir às pessoas com deficiência, a normalidade perdida. Orientadas por este parâmetro ideal de normalidade, tais práticas não cessam de produzir, paradoxalmente, exclusão, marginalização e subalternização das pessoas com deficiência. "Medidas contra esta norma, as pessoas com deficiência serão sempre constituídas como Outro, como deficiente e dependente; elas nunca serão eficientes para qualificar-se como pessoas eficientes e competentes" (Moser, 2000, p. 201).

Ora, como levar adiante a questão da imitação entre jovens e crianças cegas sem, no entanto, promover uma prática de normalização? Não resta dúvida de que essa questão toca ainda no campo de estudos sobre o qual se debruçaram outros autores. Entre eles citamos os clássicos estudos de Masini (1994). A autora vem desde os anos 90 do século XX salientando a importância de que o processo de educação da criança com deficiência visual precisa pautarse nos referenciais perceptivos e sensoriais da criança, guardada a especificidade e singularidade de sua condição visual. Ancorada no referencial fenomenológico, Masini (1994) defende que o corpo é o suporte da percepção e da aprendizagem. Corpo marcado por suas singularidades. Para a autora, se o processo de educação da criança com deficiência visual estiver pautado no referencial do vidente, o que se produz é exclusão, marginalização ou ainda, uma aprendizagem cujo foco não é senão a repetição. Ancorar o processo educacional da criança com deficiência visual em referenciais que possam levar em conta as especificidades de suas condições visuais demanda intervenções situadas, posicionadas, que tomem a diferença como positividade e não como algo a ser normalizado e corrigido por um certo padrão a ser alcançado.

Cobo, Rodríguez e Bueno (2003), analisando os impasses colocados pela questão da imitação entre crianças cegas, salientam que:

É muito mais difícil e, às vezes, impossível imitar as ações dos demais por meio de outros sentidos que não sejam a visão. $\mathrm{Na}$ 
criança deficiente visual grave, mesmo quando existe algum resíduo visual, normalmente há falta de clareza e alguma distorção ou redução na distância para ver, de maneira que as ações executadas por outras pessoas são percebidas de forma imprecisa (p. 139).

Pretender que a pessoa cega faça um movimento, um gesto exatamente como o vidente faz, pode ser improcedente. Cegos e videntes têm seus modos próprios de fazer as coisas e de estar no mundo. A proposta que orienta a pesquisa que realizamos não se funda na normalização, ao contrário, investe esforços no sentido de buscar uma artesania, um fazer que se faça no encontro com o outro, com a alteridade. Seguimos pelos meandros dessa questão. E nesses becos existe um trabalho que é artesanal, que vamos compondo tal como um mosaico.

Inter-Ação

Sem a música, sentamos em roda para conversar sobre as sensações ou algo mais que tenha surgido durante a atividade: lembranças, impressões. Comentamos sobre a oficina anterior, quando fizemos os movimentos redondos como uma onda do mar, em que alguém perguntou: "Mas como é uma onda do mar"? Interessante ninguém ter se anunciado como tendo dito isso. Retomando o assunto, indagamos como imaginavam ser uma onda do mar. A maioria não tinha ideia. Um deles disse: "Eu não sei, nunca vi uma". Minnie [jovem cega, com 16 anos] tentou explicar: "É uma coisa que vai e vem de dentro para fora e de fora para dentro". Conversamos sobre esses movimentos que eles não conheciam. Propusemos o do voo de um pássaro. Perguntamos: "Como é para vocês? Vamos fazer como se fôssemos um (...)", sugerimos. Eles concordaram. Ainda sentados em roda, cada um fazia movimentos com os braços a seu modo; eram movimentos sem molejo, um tanto brutos. Até que Sherlock disse claramente que não sabia como era e que nunca tinha feito tal movimento. Chegamos junto de cada um e fizemos com eles, encostando corpo com corpo meio que por trás, movimentando os braços abertos, mostrando como nós, videntes, costumamos representar essa ação. Então coloquei uma música, levantamos e fomos "voando" soltos, pelo palco, como pássaros, cada à sua maneira. Percebemos que voavam endurecidos, com movimentos um tanto bruscos, pouco flexíveis. Ficou a questão: teria de ser diferente? Por quê?

A professora que estava presente nessa oficina, sugeriu retalhos de tecido para ajudar no molejo do movimento. Achamos ótima a ideia e ficamos de providenciá-los para outra oficina.

Nas oficinas de expressão corporal, em princípio os movimentos não são exatamente direcionados. A ideia inicial é deixar os jovens se movimentarem livremente, trabalhar a espontaneidade sem um modo determinado e correto a fazer, mesmo porque em certa medida nos questionamos a esse respeito. Correto significa comum, como todos fazem? E como todos fazem significa como os videntes fazem?

Quem não enxerga não imita gestos e movimentos corporais. Assim, a memória cinestésica, também chamada muscular, entra em ação. Ela é obtida 
por força das práticas cotidianamente construídas, graças à experiência e muita repetição. Não àquela repetição mecânica, robotizada e descontextualizada, mas às repetições próprias da exigência da vida.

Incentivamos nos jovens, então, movimentos livres para instigar descobertas e possibilidades, mas não descartamos, em contrapartida, a oportunidade de ensiná-los, principalmente quando sentimos uma forte demanda por parte desses jovens em aprendê-los, seja por que motivo for. Paradoxalmente, em algumas situações, ficam curiosos em saber, nem que seja minimamente, como determinados gestos são representados no mundo dos videntes e como executá-los.

Essa é uma forma de se sentirem acolhidos. A importância de fazer como o vidente pode ter o sentido de fazer proliferar conexões de partilha. Fazer como todos fazem é tomar parte e, acrescido a isso, devemos levar em conta o fato de se tratar de jovens, idade na qual o desejo de aceitação está especialmente presente. Refletindo com Rancière (2005), essa pode ser uma forma de compartilhar, de se criar um mundo comum, sem distinção entre o mundo dos cegos, das pessoas com baixa visão e dos videntes.

Inter-Ação

\begin{abstract}
Pimentinha [jovem com baixa visão, com 15 anos de idade] comentou que, na atividade de relaxamento corporal, não havia diferença entre ele próprio, que enxergava pouco, e Sherlock que não enxergava nada. Ele disse que os dois tinham as mesmas possibilidades nessa questão do relaxamento. Sherlock completou que achava que o colega estava querendo dizer que não fazia diferença quanto à atividade corporal entre enxergar ou não. No intuito de esclarecer uma dúvida, perguntei a Sherlock o que achou quando direcionamos os movimentos mostrando como fazer, na prática, fazendo junto, corpo a corpo; e como ficou para ele quando propomos movimentos (representações) que os videntes fazem habitualmente e mostramos fazendo junto da mesma forma. Ele falou: "Aí, depende, mas acho que na questão do corpo não tem nada que altere, assim, 'pra' gente que não enxerga, é mais noutros casos, assim (...)". Ele não vê problema quando se ensina determinado movimento fazendo junto com ele; aliás, disse ele: "Desse jeito é bem melhor de entender do que alguém só falando sem mostrar como se faz".
\end{abstract}

Pimentinha ao opinar que não via diferença entre ele, que tem baixa visão, com bom grau de visão mantida, e Sherlock, que é cego, estava se referindo, como ele mesmo disse, à atividade do relaxamento. Sherlock, no entanto, entendeu de outro modo. Da maneira como explicou o que o colega havia dito, ficou claro que ele quis dizer não haver diferença entre cegos e videntes quanto às atividades corporais, talvez porque guardasse boa memória visual, pois até cerca de três ou quatro anos atrás tinha baixa visão com bom grau de visão mantida. 
$\mathrm{Na}$ prática profissional da primeira autora deste texto, foi possível notar alguma diferença na postura corporal e na movimentação dos jovens cegos em relação àqueles que têm baixa visão, assim como nas questões relacionadas com a aprendizagem escolar. Enquanto um usa a escrita em Braille, o outro usa em tinta, como os videntes, ainda que com a utilização de recursos específicos.

Observamos que qualquer grau de visão mantida influi na postura e nos movimentos. Por pequeno que ele seja, seu uso é permanentemente solicitado nas situações do cotidiano. Assim, podemos supor que alguma referência visual se faz presente, ainda que possa ser um tanto borrada e pouco nítida, necessitando de complementação por outras sensorialidades.

O jovem cego, ao contrário, usa exclusivamente as referências obtidas pela integração de outras sensorialidades. Desse modo, as posturas e a movimentação se instauram por distintos processos e se refletem de diferentes maneiras. É muito frequente observarmos posturas e movimentos corporais muito próximos entre pessoas que usam como principal fonte de referência a visão: os videntes e os que têm baixa visão, distintamente daquelas adotadas pelas pessoas cegas.

São inúmeros os aspectos que entram nesse processo: a intensidade da visão mantida, se, e como é usada, se é central ou periférica, congênita ou adquirida, se há memória incorporada, e os efeitos produzidos com base nas conexões engendradas por essas pessoas ao longo da vida, só para destacar alguns.

Ao longo do tempo, temos acompanhando essa diversidade de situações sendo colocadas juntas, amarradas no mesmo saco, com o rótulo da deficiência visual. Temos a ambição, com esta pesquisa, de interferir também neste ponto, convocando uma reflexão mais minuciosa e cuidadosa. Com as práticas da oficina e as crianças da Estimulação Precoce, notamos que essa ordenação de coisas da maneira como está instituída deve ser mais cuidadosamente questionada, repensada e revista. O termo deficiência visual inclui cegos e pessoas que têm baixa visão, acentuando, desse modo, o peso que carrega a palavra deficiência. A generalização não nos parece fazer avançar no conhecimento da cegueira e da baixa visão, isso porque ela parece operar com uma força que apaga as potencialidades e singularidades de cada um. Moraes (2010) aponta que: "Na escolha dos termos há um jogo político fortíssimo, articulado a um embate sobre o que contará ou não como realidade: política ontológica" (p. 45). "Cegueira" é um termo afirmativo, que traduz mais exatamente aquele que não enxerga, e "baixa visão" refere-se àquelas pessoas que têm certo grau de visão mantida que Ihe permite usá-la de modo funcional.

Essa política conservadora de ordenação que usa a generalização, afastando-se das singularidades vividas pelas pessoas que estão nessas situações, parece simplificar uma questão no mínimo complexa. Law (2003) afirma, quando discute os métodos de pesquisa, que o mundo é uma grande 
confusão e que não nos cabe apagá-la, antes devemos vivê-la, pois são realidades múltiplas que nos conformam.

Freire (1978), em seu estudo sobre este tema, afirma que:

As crianças com visão parcial estão de certa forma no limbo: não são cegas nem têm visão perfeita. Elas têm que viver ambiguamente, pois algumas pessoas esperam que se comportem como se enxergassem perfeitamente e outras as tratam como se fossem cegas. Não existem muitas pesquisas sobre essas crianças, o que sugere que elas não são vistas como muito diferentes de seus companheiros normais. Entretanto, parece provável que encontrem mais problemas em se ajustar à sua limitação, devido às expectativas conflitantes das pessoas que as cercam - algumas exigem-lhes demais e outras não esperam o suficiente. Em geral, elas se assemelham às crianças normais, embora tendam a ser, de certo modo, desajeitadas, porque não enxergam bem. Geralmente, necessitam de ajuda especial em sua educação (p. 108).

Inter-Ação

Todos preferiram trabalhar com música. Então, levantamos, ficamos de pé novamente em roda e de mãos dadas e ao som da música retomamos a atividade. Fizemos movimentos livres e depois em duplas, de frente um para o outro; com os braços estendidos à frente do corpo, de mãos dadas e dedos entrelaçados, sugerimos movimentos para a frente e para trás.

Cada um fazia como entendia, pois notei que não conseguiam imitar exatamente conforme sugeríamos. Fomos nos aproximando de cada dupla e fazendo um pouco junto com eles. Alguns disseram "legal"! (...) Quanto aos alunos cegos, faziam movimentos "um tanto duros", com muito pouca flexibilidade. Notei-os mais apreensivos, com um sorriso meio tenso no rosto.

Ficou a questão da dinâmica corporal dos alunos que têm baixa visão e dos cegos, a questão do modelo ou referência e, da imitação pela visão. Existem movimentos corretos a se fazer?

Retomando a questão do modelo, seria importante copiar os movimentos que correspondem às representações instituídas pelos videntes, como o voo dos pássaros, para serem aprendidos pelos cegos? Sherlock considerou que na questão corporal vê as mesmas possibilidades entre videntes e cegos, mas acha bom quando alguém lhe ensina os movimentos fazendo junto, e parece que não vê problema quanto a assumir algumas representações dos videntes.

Moraes (2010), em sua pesquisa de experimentação corporal com pessoas cegas e com baixa visão junto à oficina de teatro do IBC, comenta que a jovem que assumia o papel de bailarina não queria representá-la de qualquer maneira só porque era cega. Ela queria se esmerar, observar os detalhes, fazer bonito para sua mãe que estaria a assisti-la. Esse era um motivo mais que justo e compreensível, essa era sua demanda. E por que não?

Algumas vezes, temos a impressão de que os jovens ficam inibidos ou inseguros em executar os movimentos à maneira deles, sem um "modo certo" como todo mundo faz, sem um modelo ou uma referência. Talvez sintam que do 
jeito deles o movimento pode parecer estranho, engraçado, sujeito a críticas, pois não sabem bem como executá-los.

Parece que nesse contexto se apresentam os aspectos relativos à estética do movimento. Sem dúvida, os jovens se preocupam com ela, queriam tomar parte e fazer como todos fazem. Essa é uma maneira de sentirem-se incluídos.

Ressaltamos aqui as tensões registradas nas linhas de cruzamento entre o modelo visuocêntrico, hegemônico e universalista da normalidade dos gestos e o reinventar-se diante da cegueira com seus modos próprios, sem as impossíveis ou distantes referências visuais. As pessoas cegas e com baixa visão também são atravessadas pela concepção do senso comum, que as colocam em um lugar de subjugação ao modelo visuocêntrico, tornando conflitantes as tensões que daí decorrem. Por outro lado, acrescenta Bueno (2003):

O conhecimento da precisa relação entre visão e movimento não é muito exato. Se a visão provoca o movimento, ou se o movimento provoca a busca visual é ainda um tema especulativo. Entretanto, há muitos indícios de que o desenvolvimento motor seja levado a cabo mais rapidamente quando são efetuadas ações que integram visão e movimento. O fato de poder observar os movimentos do corpo ou demais movimentos requer o uso da visão, do mesmo modo, observar os objetos é também um estímulo à execução de movimentos corporais como engatinhar, ficar de pé ou caminhar para poder chegar ao elemento que interessa (p. 149).

A ausência de estimulação para as crianças cegas pode ter efeitos negativos. Como ela não vê os brinquedos em seu ambiente, pode não se interessar por eles e não tentar alcança-los. Em casos como esse, a criança não encontra motivação para se deslocar, podendo se tornar passiva.

Fazemos, então, uma ressalva neste ponto. Ensinar alguns movimentos ou fazê-los junto com a criança que não pode imitar visualmente não é impor uma representação do mundo visto com os olhos que ela jamais vai alcançar, porque de fato ela não enxerga. Também não quer dizer que ela deva ser largada à própria sorte, pois, se não houver intervenção adequada naquele momento, ela não progredirá. Os atrasos podem se suceder e criar obstáculos a seu desenvolvimento. Há de se habitar esse meio, criar possibilidades para que ela possa perceber os movimentos negociando com ela. Assim, o imitar passa a ser carnal, melhor dizendo, feito corporalmente pelo movimento junto, sentido. Desse modo, pode ser literalmente incorporado por ela.

Cria-se, assim, um campo de experimentação no qual a criança pode se reinventar, compor ou recompor esses laços com o mundo que a falta da visão de fato impede. Em conexão com o corpo do adulto, com os movimentos juntos, com as sensações, com a voz e com os sons do brinquedo, com as pistas sensoriais do ambiente, ela vai construindo possibilidades de autonomia. Assim, conforme salienta Latour (2012), a autonomia é definida não por uma 
capacidade de agir sozinho, mas ao contrário, por uma capacidade de agir que é ampliada na medida em que se ampliam as conexões entre corpo-mundo. Para conquistar autonomia, em uma palavra, é preciso fomentar, ampliar e consolidar mais e mais as conexões corpo-mundo, sejam conexões que ligam humanos a humanos, sejam aquelas que ligam humanos a não humanos.

A autonomia, então, é uma conquista; é galgada, suada, modelada e remodelada a cada conexão, seja para sentar, rolar, colocar-se de pé ou andar. Quanto mais conexões, mais se produzem efeitos propulsores de sua independência. Importante salientar que não defendemos a autonomia como um fazer sozinho. Autonomia é um efeito das conexões que se tecem entre corpo e mundo. As conexões ampliam a capacidade de agir. Daí a relevância do trabalho de expressão e experimentação corporal com crianças e jovens cegos. A experimentação do corpo é uma via de acesso à ampliação das conexões corpomundo.

Não resta dúvida de que neste processo de imitação encarnada, situada, vivida e partilhada o pesquisador também se transforma porque seus gestos mais do que impostos, vão sendo também modelados no encontro com o outro. A transformação é, pois, uma via de mão dupla.

\section{CONSIDERAÇÕES FINAIS}

Inter-Ação

Como as crianças cegas e algumas com baixa visão não podem imitar visualmente, temos o cuidado de mostrar-Ihes como fazer os movimentos e executar alguns deles fazendo junto com elas, corpo a corpo, até que possam realizá-los sozinhas, bem como orientamos seus pais a fazerem o mesmo. $O$ movimento, quando realizado por trás e lateralmente à criança, assegura uma noção mais exata.

Desde o início do desenvolvimento, o comportamento da criança é motivado pela observação visual. Participar com os colegas e interagir com eles depende, em grande parte, de poder observar as ações e responder a elas (Cobo et al., 2003). Esses autores afirmam que "ser capaz de fazer o que as outras crianças fazem é um fator crucial para ser aceito pelos amigos e adultos" (Cobo et al., 2003, p. 139).

Na prática com as crianças da Estimulação Precoce, é fundamental ensinar os movimentos mais diretamente envolvidos nas atividades da vida diária (AVDs), como caminhar, comer, levar o copo à boca, despir-se e vestir-se, estimulando e promovendo as respectivas conexões com a parede, a colher, o prato, o copo, as roupas. Executamos, várias vezes, o movimento junto, por trás e lateralmente à criança, fazendo como se fôssemos nós ela mesma, assegurando, desse modo, uma noção mais exata dele, e orientamos seus pais a 
fazerem da mesma forma. Halliday (1975), há algumas décadas, já sublinhava que:

A criança que tem uma limitação visual necessita mais do que as outras de sentir o prazer de se movimentar e saber "como" se movimentar no espaço, de maneiras diferentes. Muitas vezes é preciso mostrar-lhe especificamente como movimentar-se. Ela pode não enxergar o suficiente para ver como é feito. Deste modo estas atividades devem ser executadas bem perto da criança, para que ela perceba como são feitas. Às vezes será necessário "ver" com as mãos para obter uma noção de como é executada uma certa atividade (p. 34).

Inter-Ação

Na alimentação com independência, com a utilização da colher é necessário ensinar o movimento por trás, fazendo junto, pois a criança cega não vê o prato e não sabe de antemão o trajeto até a boca. Acrescida à questão da ausência de imitação visual encontra-se a de ela não ter, ainda, a necessária coordenação motora, uma vez que não se constitui em uma coordenação visuomotora. Nesses casos, como em muitos outros, a coordenação é tátil-motora, ou cinestésica, instituída pela prática desses movimentos, que não devem ser realizados de forma mecânica, mas sempre contextualizada. Essas e outras atividades, que muitas vezes pensamos ser "automáticas", requerem a orientação pela visão, portanto em sua falta precisam ser ensinadas repetidas vezes até que possam ser realizadas com autonomia.

A marcha e os movimentos que a envolvem também devem ser estimulados e ensinados. Lembro-me em especial de uma criança cega congênita, de idade por volta de três anos, que não fazia a menor ideia da maneira de movimentar as pernas para caminhar, chegando mesmo a virá-las totalmente, sem a menor noção. Era um trabalho praticamente artesanal. Era preciso mostrar-lhe fazendo junto com ela, muitas vezes colocando-a sobre os meus pés, com seu corpo virado para a frente andando junto, fazendo-a sentir exatamente o movimento.

Quase sempre elas precisam dessa estimulação inicial para desenvolver sua motricidade, ou melhor, sua psicomotricidade, para rolar, sentar, ficar de quatro apoios (raramente engatinham), colocar-se de pé e caminhar com independência. Temos observado que a aquisição da marcha com independência tem sido um marco em suas vidas e também na de suas famílias. Ao caminhar, a criança rompe o espaço, explora e busca conhecer tudo que a cerca, encarando desafios. Sem dúvida a aquisição da marcha é um forte indício do desenvolvimento.

O mundo que é visto por quem enxerga precisa ser apresentado mais cuidadosamente a quem não enxerga. 
Trata-se, antes de tudo, de uma ação conjunta. Não é obvio nem está dado o que é necessário fazer para que aquela criança que não tinha noção do posicionamento das pernas se coloque de pé. O trabalho é artesanal e depende de uma ação inventiva conjunta. Não são todas as crianças cegas que têm dificuldade de alinhar as pernas para andar, mas essa, em especial, nos apresentou tal questão.

Cada criança tem uma demanda que Ihe é própria; as crianças cegas não são todas iguais. Não existe um protocolo ou repertório exato preestabelecido de como proceder em cada caso. É isso que exige do vidente uma transformação, um aprender com eles o que é necessário ser feito; exige um manejo, certa artesania, um criar juntos. Existe aí uma via de mão dupla, do vidente para o cego e também do cego para o vidente.

Na oficina de expressão corporal, no entanto, a ideia é criar um espaço no qual os jovens possam se soltar, deixar fluir e experimentar os mais variados movimentos, criar oportunidade para que possam inventá-los e reinventá-los à maneira deles, cavando-os nas brechas e interstícios entre eles. Sem convocálos necessariamente à imitação, mas sem impedir, em contrapartida, essa ação, desde que faça sentido para eles, compreendendo que esta pode ser uma demanda singular e relevante. Pretendemos, antes de tudo, criar um espaço de possibilidades.

Discutindo a questão da necessidade da imitação dos gestos dos videntes por parte dos jovens cegos e com baixa visão para estabelecer uma boa comunicação com eles, Cunha (2004), em sua prática na oficina de teatro do IBC, tem a declarar que:

Não que a aprendizagem destes gestos tradicionais seja condenável. Acreditamos, no entanto, que a mesma deva partir da necessidade e do desejo do próprio deficiente visual. Não algo imposto e encarado como imprescindível à sua vida. É uma informação a mais, que pode ser utilizada ou não. E partindo da sua necessidade, do seu desejo, esse gesto estereotipado deixa de ser algo vazio e passa a ter um sentido, um contexto (p. 13).

Então, a questão da imitação e da representação dos movimentos não é tão simples como à primeira vista poderia parecer. Há que se ter um certo manejo, uma sensibilidade para perceber e lidar com essa demanda, a partir de cada situação, de acordo com suas singularidades e circunstâncias. É certo, no entanto, que a artesania a que nos referimos não significa apenas dizer que cada caso é um caso, fazendo dessa afirmação um puro relativismo. Antes de tudo, a aposta que fizemos nesse texto aponta para uma direção ética do trabalho com a criança e o jovem com deficiência visual: o fazer com o outro (Moraes, 2010). Isso significa apostar e investir na possibilidade de que a criança e o jovem cego indiquem os caminhos a seguir. Significa ainda tomar a pessoa com deficiência visual como agente, como sujeito ativo no processo de aprender, capaz de 
indicar as singularidades das suas formas de perceber o mundo (Masini, 1994). O processo de educação da pessoa com deficiência visual, a partir do que expusemos nesse trabalho, está pautado nas singularidades do perceber e do relacionar-se das pessoas cegas.

Seguindo as pistas de Mol (2008) salientamos ainda que a força das pesquisas situadas está justamente em abrir a possibilidade de que seus achados engendrem novas sensibilidades, novos projetos de pesquisa cujo norte éticopolítico encontrem ressonâncias com as proposições dos autores. Assim, Mol (2008) salienta que o bom estudo de caso inspira uma teoria, amplia a sensibilidade, engendra uma trajetória dinâmica na qual uma certa direção de pesquisa se desloca para outros cenários, mobiliza outros atores. Se este for um dos efeitos desse trabalho, consideramos que fomos exitosas.

\section{REFERÊNCIAS}

Brasil. (2001). Programa de capacitação de recursos humanos do ensino fundamental: deficiência visual (vol. 1). Brasília, DF: Ministério da Educação, Secretaria de Educação Especial. Recuperado de http://portal.mec.gov.br/seesp/arquivos/pdf/def_visual_1.pdf

Bueno, S. T. (2003). Motricidade e deficiência visual. In M. B. Martin, \& S. T. Bueno (Eds.), Deficiência visual (M. L. Pedro, Trans., cap. IX, p. 145-154). São Paulo, SP: Santos. (Trabalho original publicado em 2003).

Carpentieri, N. M. (2001). Um aluno especial: Um cego num mundo de videntes. In E. J. S. Martins (Org.), Diferentes faces da educação (pp. 39-56). São Paulo, SP: Arte \& Ciência Villipress.

Cobo, A. D., Rodríguez, M. G., \& Bueno, S. T. (2003). Aprendizagem e deficiência visual. In M. B. Martin, \& S. T. Bueno (Coords.), Deficiência visual: Aspectos psicoevolutivos e educativos (M. L. Pedro, Trans., cap. VIII, pp. 129-144). São Paulo, SP: Santos. (Trabalho original publicado em 2003).

Cunha, M. F. C. da. (2004). A Expressão corporal e o deficiente visual. Revista Benjamin Constant, 10(28), 8-15.

Despret, V. (2012). Experimentar a disseminação. Manuscrito não publicado.

Freire, J. (1978). Crianças com deficiências visuais. In J. Freire, A criança excepcional (cap. 6, pp. 103-113). Rio de Janeiro: Francisco Alves.

Gurgel, M., \& Moraes, M. (2014). A Touch of Play. Psychology, 5, 602-608. doi: $10.4236 /$ psych. 2014.57071

Halliday, C. (1975). Crescimento, aprendizagem e desenvolvimento da criança incapacitada do nascimento à idade escolar (A. A. Silva, J. L. Verturini, \& T. F. O. Rossi, Trans.). São Paulo, SP: Fundação para o Livro do Cego no Brasil. (Trabalho original publicado em 1970). 
Heimers, H. (1970). Como devo educar meu filho cego? (H. Schoenfeldt, Trans.). São Paulo, SP: Fundação para o Livro do Cego no Brasil. (Trabalho original publicado em 1970).

Kastrup, V. (2013). Cegos e videntes se encontram no museu: Da dicotomia à partilha do sensível. Caderno Tramas da Memória, 3, 203-224.

Latour, B. (2012). Reagregando o social: Uma introdução à teoria do ator-rede. São Paulo, SP: Edusc/UFBa.

Law, J. (2003). Making a mess with method. Lancaster: Lancaster University, Department of Sociology and Centre for Science Studies.

Manso, C. (2010). Narrativas do cegar: (Re) criações de um corpo. Dissertação de Mestrado, Programa de Pós-graduação em Psicologia, Universidade Federal Fluminense, Niterói.

Masini, E. O perceber e o relacionar-se do deficiente visual. Brasília, DF: Corde, 1994.

Mol., A. (2008). Política ontológica: Algumas ideias e várias perguntas. In J. A. Nunes, \& R. Roque (Orgs.), Objectos impuros: Experiências em estudos da ciência (pp. 63-78). Porto: Afrontamento.

Moraes, M. (2010) PesquisarCOM: Política ontológica e deficiência visual. In M. Moraes \& V. Kastrup. Ver e não ver: arte e pesquisa com pessoas com deficiência visual (pp. 26-51). Rio de Janeiro: Nau Editora/Faperj.

Moser, I. (2000). Against normalization: Subverting norms of ability and disability. Science as Culture, 9(2), 201-240. doi: 10.1080/713695234

Pozzana, L. (2013). Movimento sensível e vital: Uma oficina articulando a cegueira com o mundo. Tese de Doutorado, Universidade Federal do Rio de Janeiro, Rio de Janeiro.

Rancière, J. (2005). A partilha do sensível: Estética e política. São Paulo, SP: Eixo Experimental/Ed. 34.

Rodrigues, M. R. C. (2013). Práticas Corporais em Jovens com Deficiência Visual. Tese de Doutorado, Universidade Federal Fluminense, Niterói.

Rodrigues, M. R. C. (2002). Estimulação precoce: uma contribuição da psicomotricidade na intervenção fisioterápica como prevenção de atrasos motores na criança com cegueira congênita nos dois primeiros anos de vida. Benjamin Constant, 8(21), 6-22. Recuperado de http://200.156.28.7/Nucleus/media/common/Nossos_Meios_RBC_RevAbr20 02_A rtigo_2.rtf.

Rodrigues, M. R. C., \& Macário, N. M. (2006). Estimulação precoce: sua contribuição no desenvolvimento motor e cognitivo da criança cega congênita nos dois primeiros anos de vida. Benjamin Constant, 12(33), 1122. Recuperado de http://200.156.28.7/Nucleu s/media/common/Nossos_ Meios_RBC_RevAbr2006_A rtigo2.doc.

Sampaio, E. (2013). Ferramentas cognitivas e tecnológicas para inclusão social de pessoas com deficiência visual. Benjamin Constant, 19(n. esp.), 30-41. 
Silva, C. H., \& Grubits, S. (2004). Discussão sobre o efeito positivo da equoterapia em crianças cegas. Psicologia: Revista de Psicologia da Vetor Editora, 5(2), 06-13. Recuperado de http://pepsic.bvsalud.org/scielo.php?pid=S1676$73142004000200002 \&$ script=sci_arttext

Sobre os autores

Maria Rita Campello Rodrigues é bióloga pela Universidade Santa Úrsula e fisioterapeuta pelo Instituto Brasileiro de Medicina de Reabilitação, mestre em Ciência da Motricidade Humana pela Universidade Castelo Branco e doutora em psicologia pela Universidade Federal Fluminense. Trabalha na linha Ciência da Motricidade Humana, Estimulação Precoce e Deficiência Visual.

mariaritacampello@gmail.com

Marcia Oliveira Moraes é Professora Titular no Instituto de Psicologia da Universidade Federal Fluminense, com atuação na graduação e na pós-graduação (strito sensu) em Psicologia na mesma instituição. É psicóloga pela Universidade Federal Fluminense, mestre em Psicologia pela Universidade Federal do Rio de Janeiro e doutora em Psicologia Clínica pela Pontifícia Universidade Católica de São Paulo. Trabalha na linha epistemologia da psicologia, teoria ator-rede e os estudos de ciência, tecnologia e sociedade (CTS) em suas interfaces com a psicologia e com os estudos da deficiência. Recebe financiamento de pesquisa da Faperj e do CNPq. marciamoraes@id.uff.br

Recebido em: 19/10/2015

Revisado em: 04/03/2015

Aceito em: 07/03/2015 